\title{
Ara C face: Cytarabine related dermatological toxicity
}

\author{
Manideepa Maji ${ }^{1}$, Nita Radhakrishnan² \\ ${ }^{1}$ Indian Academy of Pediatrics Fellow, ${ }^{2}$ Associate Professor and Head, Department of Pediatric Hematology Oncology, \\ Super Speciality Pediatric Hospital and Post Graduate Teaching Institute, Noida, Uttar Pradesh, India
}

Cutaneous complications due to cytarabine are often seen in patients with hematological malignancy. The usual toxic drug eruptions are acral erythema which occurs as a result of accumulation of drug and its metabolites in the sweat glands. This manifests as not only redness, but pain, swelling, itching, and peeling of skin of hands and feet and at times the trunk. We describe drug induced erythema that developed predominantly on the face of a child with acute myeloid leukemia. An 8-year-old girl of acute myeloid leukemia with FMSlike tyrosine kinase 3 internal tandem duplication positive status on induction chemotherapy with cytarabine at ad dose of $100 \mathrm{mg} / \mathrm{m}^{2} /$ dose twice a day developed erythematous, maculopapular, and itchy rashes on $4^{\text {th }}$ day of treatment involving face, bilateral upper limb and anterior chest. There were no blisters, conjunctival, or mucosal involvement. The rash was well tolerated after symptomatic treatment and improved after $28^{\text {th }}$ day of treatment. Although the rash looks aggressive, there were no associated symptoms and disappear without subsequent sequelae. Due to benign nature of this rashes, cytarabine therapy should not be stopped.

Key words: Acute myeloid leukemia; Cytarabine; Skin toxicity

\section{Access this article online}

Website:

http://nepjol.info/index.php/AJMS DOI: 10.3126/ajms.v13i1.40327

E-ISSN: 2091-0576

P-ISSN: 2467-9100

Copyright (c) 2022 Asian Journal of Medical Sciences

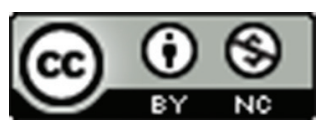

This work is licensed under a Creative Commons Attribution-NonCommercial 4.0 International License.

\section{INTRODUCTION}

Cytarabine or cytosine arabinoside is an integral part of treatment of acute myeloid leukemia (AML). Cutaneous reaction such as erythematous rashes is rare but known benign side effect of cytarabine. They are usually noted on hands and feet thus leading to the popular. Therefore, correct attribution of the cause of skin reaction is important for appropriate management and early counseling of parents to ameliorate their anxiety.

\section{CASE REPORT}

An 8-year-old girl with newly diagnosed case of high risk AML with FMS-like tyrosine kinase 3 internal tandem duplication positive status, was started on induction chemotherapy with cytarabine $\left(100 \mathrm{mg} / \mathrm{m}^{2} /\right.$ dose twice a day for 10 days), daunorubicin $\left(60 \mathrm{mg} / \mathrm{m}^{2} /\right.$ day for
3 days), and etoposide (100 mg/ $\mathrm{m}^{2} /$ day for 5 days). On day 4 of treatment, child started to develop maculopapular, erythematous, non-blanching, and pruritic rashes which was initiated from bilateral upper limb, anterior chest followed by extensive involvement of face sparing nose and nasolabial fold (Figure 1). Child was managed with antihistaminics and other supportive therapy to relieve symptoms. The rash resolved gradually without scarring or hyperpigmentation on day 28 of starting of chemotherapy. Although patient was completely asymptomatic, during subsequent cycles of chemotherapy with cytarabine. She did not require any premedication.

\section{DISCUSSION}

The incidence of dermatological toxicity following chemotherapy is reported in $2-72 \%$ patients. Cytarabine 


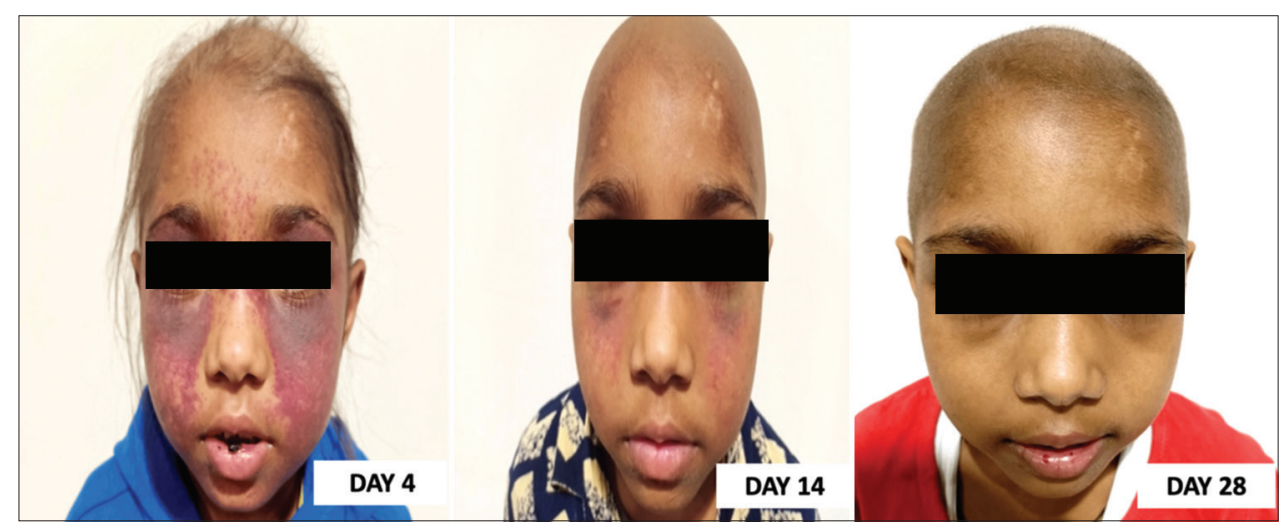

Figure 1: Timeline showing eruption of maculopapular rash on face and followed by clearing after completion of chemotherapy

is a chemotherapeutic agent which inhibits pyrimidine synthesis. This drug is effectively used in the treatment of AML. Among all side effects dermatological adverse reaction is not rare and mostly seen in high dose but varied in different studies ranging from $39 \%$ to $55 \% 0^{1-3}$ Ruben et al., showed that $18 \%$ cutaneous reactions may occur in low dose cytarabine $\left(<1 \mathrm{~g} / \mathrm{m}^{2}\right)$ also. ${ }^{4}$ There is no consensus currently on the relationship between dosage and cutaneous reactions of cytarabine. ${ }^{5}$ It is also not associated with age of patient, concurrent administration of allopurinol, or other chemotherapeutics. It is less in patients who receive concurrent steroids along with cytarabine such as in NonHodgkin Lymphoma. In our case, since it was observed in standard dose of cytarabine, histopathological examination to rule out alternative diagnoses such as leukemia cutis, Sweet syndrome, and leukocytoclastic vasculitis was not done. However, the overall clinical history such as time of onset of rash, area of involvement, and drug exposure uphold the diagnosis. As rash was transient in nature, changing of medication was not necessary but rapid evaluation of symptoms is necessary to differentiate from life-threatening infections in these fragile patients.

\section{REFERENCES}

1. Richards $\mathrm{C}$ and Wujcik D. Cutaneous toxicity associated with high-dose cytosine arabinoside. Oncol Nurs Forum. 1992;19(8):1191-1195.

2. Wright LG. Maculopapular skin rashes associated with highdose chemotherapy: Prevalence and risk factors. Oncol Nurs Forum. 2006;33(6):1095-1103. https://doi.org/10.1188/06.onf.1095-1103

3. Grille S, Guadagna R, Boada M, Irigoin V, Stevenazzi M, Guillermo C, et al. Cytarabine and skin reactions in acute myeloid leukemia. Medicina (B Aires). 2013;73(6):535-538.

4. Ruben BS, Yu WY, Liu F, Truong SV, Wang KC and Fox LP. Generalized benign cutaneous reaction to cytarabine. J Am Acad Dermatol. 2015;73(5):821-828.

5. Morio K, Mizuki M, Sozu T and Uejima E. Risk factors for cytarabineinduced cutaneous toxicity in patients with haematological malignancies. Chemotherapy. 2014;60(3):168-173.

https://doi.org/10.1159/000371839

\section{Authors Contribution:}

NR and MM- Diagnosed the patient and managed her. Both were involved in the manuscript.

Work attributed to:

Department of Pediatric Hematology Oncology, Super Speciality Pediatric Hospital and Post Graduate Teaching Institute, Noida, Uttar Pradesh, India

Source of Support: Nil, Conflict of Interest: None declared. 